\title{
COMPARISON OF ACOUSTIC SYNTHETIC JET ACTUATOR WITH ONE AND TWO DIAPHRAGMS
}

\begin{abstract}
E. Smyk*
Abstract: The paper investigates the synthetic jet actuators based on similar geometries but with another number of diaphragms or them operates conditions: one ediaphragm, one diaphragm with damped chamber or both diaphragm together. The actuators operates close to first resonance frequencies and was supply by a harmonic power input. The characteristic velocity as function of the input real power were measured. On this basis, approximate values of momentum flux, kinetic energy and efficiency were determined. The paper presented benefits of using synthetic jets actuator with two diaphragms. The used of two diaphragms increase the value of, momentum flux about $79.62 \%$, kinetic energy about $140.72 \%$ and energetic efficiency about $140.72 \%$ relative to actuator with one undamped diaphragm by the same value of real power input.
\end{abstract}

Keywords: synthetic jet, ZNMF, synthetic jet actuator

\section{Introduction}

Synthetic jets (SJs) are typically formed by momentary and periodic ingestion and expulsion of fluid at the exit of the nozzle or across an orifice. Since the average over time mass flow rate through orifice is zero during one full cycle of operation, such an SJ is also called as zero- net mass- flux (ZNMF). However, for typical operating conditions, the net flux of momentum of external flow is non zero. On the edges of expelled jet are formed vortex ring, which create non zero net flux. A devices to generation of SJ are called synthetic jet actuators (SJAs).

SJs are used mainly in active flow control (Tesař et al., 2012; Trávnícek et al., 2014) and in cooling systems (Trávníček \& Tesař, 2003). The possibility of them application most often depends on SJs momentum flux and velocity. It is especially important in case of them application in wind turbines due to their impact on the surrounding environment (Karwowska et al., 2015, Mikołajczak et al., 2013). Therefore it seeks solutions to increase efficiency of SJAs for example by using of twin jets (Greco et al., 2014), multiple synthetic jets (Paolillo et al., 2017) or hybrid synthetic jet (HSJ) (Tesař et al., 2007).

Kordík et al. (2015) compare velocity and energetic efficiency of SJ and HSJ. They analyze two acoustic actuators (SJA, HSJA) each with two loudspeakers diaphragms as executive elements. The HSJA achieves a $15-23 \%$ increase in velocity and $41-48 \%$ increase in the energetic efficiency, in comparison with the ordinary synthetic jet actuator operating at the same input real power. Kordík et al. (2015) presented efficiency resonance curve of used SJA and HSJA acquired at five constant input real powers. Energetic efficiency at real power equal $0.2 \mathrm{~W}$ was almost $6 \%$ and at $3.2 \mathrm{~W}$ was about $3 \%$. For comparison (Gil \& Strzelczyk 2016) obtained energetic efficiency almost 5\% for one of nine different investigated SJA, but Kordík \& Trávníček (2017) demonstrated that it is possible of SJA increasing energetic efficiency to even $15 \%$ in case of nozzle diameter optimization. Despite this in opinion of author of this paper, it should think about possibility of energetic efficiency increasing by two executive elements in SJA using.

* Emil Smyk, MSc.: Department of Mechatronics and Engineering Machines, UTP University of Science and Technology, Al. Prof. S. Kaliskiego 7, 85-796 Bydgoszcz, PL, emil.smyk@utp.edu.pl 


\section{Observed parameters}

The most primary parameter of SJs, which is going to be observed and evaluated during the current experiment is the characteristic velocity of the SJ. This velocity is evaluated as follows:

$$
U_{0}=\frac{1}{S_{n}} \frac{1}{T} \int_{0}^{T_{E}} \int_{S_{n}} u \mathrm{~d} S \mathrm{~d} t
$$

where $S_{n}$ is the nozzle exit cross-sectional area, $u$ is the instantaneous velocity component, $T_{E}$ is the extrusion stroke part of period, $T$ is the actuation period.

The another integral quantities, which will be going analyzed, are: the time average momentum flux $M_{0}$, kinetic energy $E_{0}$ and power efficiency of SJA $\eta$ :

$$
\begin{gathered}
M_{0}=\frac{1}{T} \int_{0}^{T_{E}} \int_{S_{n}} \rho u|u| \mathrm{d} S \mathrm{~d} t \\
E_{0}=\frac{1}{T} \int_{0}^{T_{E}} \int_{S_{n}} \frac{\rho u^{3}}{2} \mathrm{~d} S \mathrm{~d} t \\
\eta=\frac{0.5 \rho S_{n} U_{0}^{3}}{P_{R M S}}
\end{gathered}
$$

where $\rho$ is density of working fluid, $P_{R M S}$ is real electrical power of SJA.

\section{Experimental setup}

Figure 1 shows the schematic view of the tested SJA. Actuator consist two opposite speaker Monacor SP6/8SQ mounted on a metal ring. On his circuit are made 24 holes with diameter Ø3. On ring are attached two sleeves so as to create between them a gap of $0.5 \mathrm{~mm}$ (nozzle of SJA). One of sleeve creates from the back of the speaker closed chamber. A analysis of closed chamber influence on generated SJ was presented in the (Smyk, 2017). Loudspeakers operate in opposite directions, what means that they operate in the same phase. The measurements were done in three different settings: with one diaphragm without damping chamber (Case 1), with one damped diaphragm (Case 2) and with two diaphragms (Case 3). Unsupplied diaphragm was mechanically fixed.

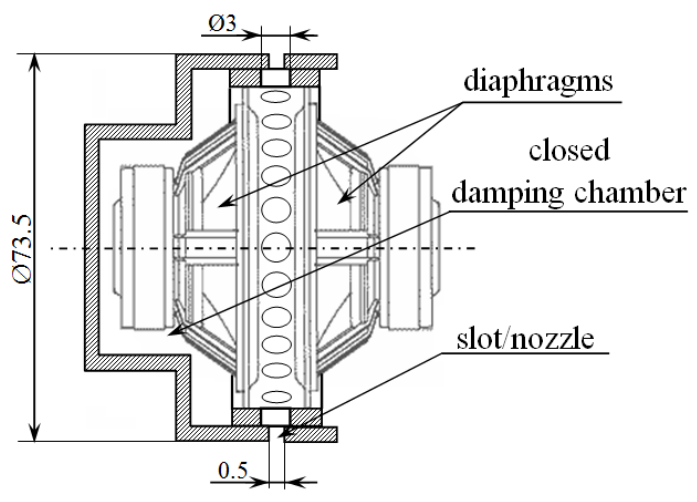

Fig. 1: Schema of the current synthetic jet actuator

During all experiments, the loudspeakers was supplied by a harmonic electric current generated by Rigol DG4162 waveform generator and gained in SeoUm Pa-940/2 amplifier. During experiments was used only one current frequency $f=147 \mathrm{~Hz}$, which suits to characteristic frequency of tested SJA in case 3 .

To velocity measurements was used MiniCTA 55T30 Dantec Dynamics hot- wire anemometer with a single wire probe 55P16 and NI9215 data acquisition device. The sampling frequency of hot wire signal was $f=25 \mathrm{kHz}$ and the number of samples was $n=1024$. The characteristic velocity of SJ was calculated on the basis six periods of actuator operation, thanks to such a choice of measurements parameters. The temperature of working fluid was measured using 90P10 probe. The temperature correction of the hot-wire probe data was done. 


\section{Experimental results}

In the Figure 2a was showed characteristic velocity of SJ, as a function of the real power. In Case 1 value of characteristic velocity is higher about 15 times then in case 2, by real power bellow $1 \mathrm{~W}$. The higher supply power the lower difference between this value. By real power $6.8 \mathrm{~W}$ the characteristic velocity in Case 1 is higher 4 times then in Case 2. The value of characteristic velocity in Case 3 is larger than value of velocity in Case 1, but smaller than simple sum of SJ velocity in Case 1 and Case 2.

In the Figure 2a were additionally demonstrated approximation of characteristic velocity in real power domain with applied equation. Below each equation is presented square of correlation coefficient value. In each case correlation coefficient is higher than 0.9 and it mean almost full correlation (classification according to J. Guilford). Therefore, to complete of Figure $2 b$, c, d was used velocity values calculated from formulas presented in the Figure 2a. So it should be highlighted that a presented charts are approximation done on the basis of measurements presented in Figure 2a. Because in Case 2 the smallest real power of supply was $0.84 \mathrm{~W}$ (by smaller value the velocity was too small to be measured by the method used) and the biggest was $7 \mathrm{~W}$ the Figure $2 \mathrm{~b}, \mathrm{c}, \mathrm{d}$ was discussed only in this range of power values. The differences between the analysis values are specified relative to parameters of SJA with two diapghrams (Case 3).
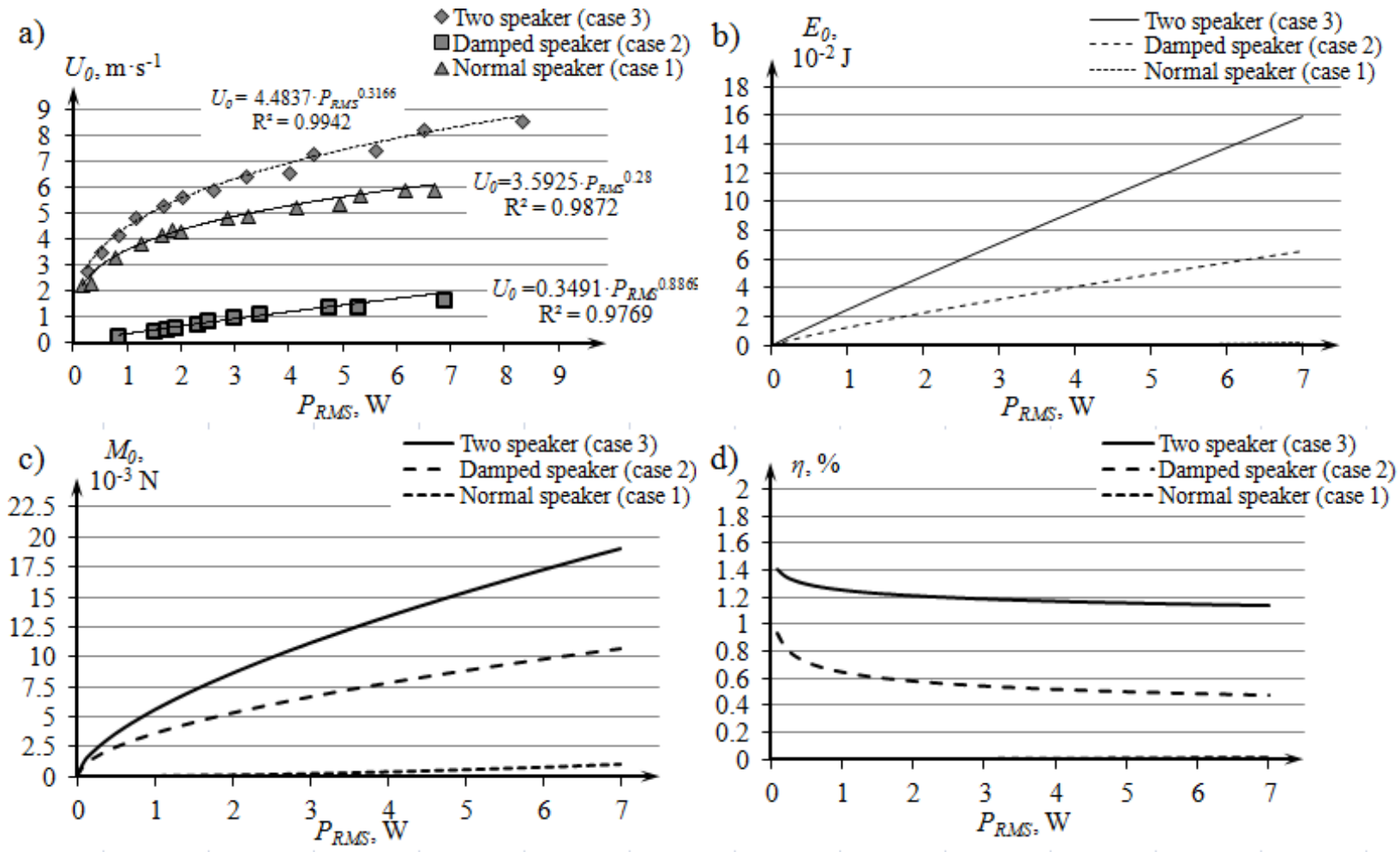

Fig. 2: Power characteristic of synthetic jets actuators with one, one dumped and two diaphragms. (a) characteristic velocity $U_{0},(b)$ kinetic energy $E_{0},(c)$ momentum flux $M_{0}$ and (d) electrical efficiency, as a function of the real power

In the Figure $2 b$ are presented kinetic energy of SJ and in Figure $2 c$ momentum flux, as a function of the real power. Dependance of SJ kinetic energy on real power is practicaly linnear. By input real power $1 \mathrm{~W}$ the kinetic energy in Case 1 is smaller by $48.56 \%$ then in Case 3 . This differenct increes with the value of power input. By power $7 \mathrm{~W}$ the value of kinetic energy in Case 3 is larger than in Case 1 about 58.48\%. In Case 2 the maximum value of SJ kinetic energy is $0.21 \cdot 10^{-2} \mathrm{~J}$. Similar dependence occur in the case of momentum flux (Figure 2c). The value of momentum flux in Case 3 is larger by $44.33 \%$ than in Case 1 . The maximum value of momentum flux in Case 2 is $1.07 \cdot 10^{-3} \mathrm{~N}$.

In the Figure $2 d$ are presented electrical efficiency of SJA, as a function of the real power. By input real power $1 \mathrm{~W}$ the electrical efficiency of SJA in Case 1 is smaller by $48.56 \%$ then in Case 3 . By power $7 \mathrm{~W}$ efiiciency in Case 1 is $0.91 \%$, in Case 2 is $0.02 \%$, and in Case 3 is $1.13 \%$. Efficiency in Case 2 is the larger the larger is the power. 
The closed chamber behind one of diaphragm has significant influence on a SJA parameters. The tested parameters are repeatedly lower in Case 2 than in Case 1. It must be noted, that the efficiency in Case 2 increases with the real power. Normally this relationship is reversed (Tesař et al. 2007; Gil \& Strzelczyk 2016). The SJA in Case 3 had larger parameters than SJA in Case 1 only by real power above 1W. It can be caused by too small real power supplied damped loudspeaker. SJA in Case 2 did not generate SJs by so small supply real power, and in Case 3 the dumped loudspeaker can affect negatively on second diaphragm.

\section{Conclusion}

I the paper investigates three synthetic jet actuators based on similar geometries, but with different the number or conditions in which the diaphragms operated. The investigation was performed within the domain of input real power into the actuator by frequency $147 \mathrm{~Hz}$. This frequency is near characteristic frequency of tested SJAs. Dependence of characteristic velocity, as a function of the real power, was evaluated from hot-wire experiments. On this basisi was calculated SJs kinetic energy, momentum flux and SJAs energetic efficiency.

The application of two executive elements was favorable. The used of two diaphragms increase the value of, momentum flux about $79.61 \%$, kinetic energy about $140.72 \%$ and energetic efficiency about $140.72 \%$ relative to actuator with one undamped diaphragm by the same value of real power input $(7 \mathrm{~W})$.

Parameters increase is satisfactory and proves that the use of SJA with two executive elements can increase the electrical efficiency, compared to the actuator with one diaphragm. The use of two undamped diaphragms probably increase even more operations parameters.

\section{Acknowledgement}

Scientific work financed from the budget for science in the years 2015/2018 as a research project within the program under the name "Diamond Grant". Author also received instructional support BSM-60/2017 and BS- 16/2013 guaranteed by Faculty of Mechanical Engineering of UTP University.

\section{References}

Gil, P. and Strzelczyk, P. (2016) Performance and efficiency of loudspeaker driven synthetic jet actuator. Experimental Thermal and Fluid Science, 76, pp. 163-174.

Greco, C.S., Ianiro, A. and Cardone, G. (2014) Time and phase average heat transfer in single and twin circular synthetic impinging air jets. International Journal of Heat and Mass Transfer, 73, pp. 776-788.

Karwowska, A., Mikoajczak, J., Dolatowski, Z.J. and Borowski, S. (2015) the effect of varying distances from the wind turbine on meat quality of growing-finishing pigs, Annals of Animal Science, 15, 4, pp. 1043-1054

Kordík, J. and Trávníček, Z. (2017) Optimal diameter of nozzles of synthetic jet actuators based on electrodynamic transducers. Experimental Thermal and Fluid Science, 86, pp. 281-294.

Kordík, J., Trávníček, Z. and Pavelka, M. (2015) Energetic efficiencies of synthetic and hybrid synthetic jet actuators driven by electrodynamic transducers. Experimental Thermal and Fluid Science, 69, pp. 119-126.

Mikołajczak, J., Borowski, S., Marc-Pienkowska, J., Odrowaz-Sypniewska, G., Bernacki, Z., Siodmiak, J. and Szterk, P. (2013) Preliminary studies on the reaction of growing geese (Anser anser $\mathrm{f}$. domestica) to the proximity of wind turbines, Polish Journal of Veterinary Sciences, 16, 4, pp. 679-686.

Paolillo, G., Greco, C.S. and Cardone, G. (2017) The evolution of quadruple synthetic jets. Experimental Thermal and Fluid Science, 89(April), pp. 259-275.

Smyk, E. (2017) Interference in axisymmetric synthetic jet actuator. EPJ Web of Conference, 143, EDP Sciences p. 2111.

Tesař, V., Trávnícek, Z., Kordík, J. and Randa, Z. (2007) Experimental investigation of a fluidic actuator generating hybrid-synthetic jets. Sensors and Actuators A: Physical, 138(1), pp. 213-220.

Tesař, V., Broučková, Z., Kordík, J., Trávnícek, Z. and Peszyński K. (2012) Valves with flow control by synthetic jets. EPJ Web of Conferences, 25, EDP Sciences, p.1092.

Trávnícek, Z., Tesař, V., Broučková, Z. and Peszyński K. (2014) Annular impinging jet controlled by radial synthetic jet. Heat Transfer Engineering, 35(16), pp. 1-12.

Trávníček, Z. and Tesař, V. (2003) Annular synthetic jet used for impinging flow mass-transfer. International Journal of Heat and Mass Transfer, 46, pp. 3291-3297. 